\title{
Homojenleştirme Süresinin Mg-Al-Sn-Mn-La-Gd Alaşımın Aşınma Davranışı Üzerindeki Etkisinin İncelenmesi
}

\author{
İsmail Hakk1 Kara ${ }^{1 *}$ \\ 1* Karabük Üniversitesi, Mühendislik Fakültesi, Metalurji ve Malzeme Mühendisliği Bölümü, Karabük, Türkiye, (ORCID: 0000-0001-8425-5649), \\ ihakkikara@karabuk.edu.tr
}

(İlk Geliş Tarihi 21 Ekim 2021 ve Kabul Tarihi 16 Aralık 2021)

(DOI: 10.31590/ejosat.1013166)

ATIF/REFERENCE: Kara, İ.H., (2022). Homojenleştirme Süresinin Mg-Al-Sn-Mn-La-Gd Alaşımın Aşınma Davranışı Üzerindeki Etkisinin İncelenmesi. Avrupa Bilim ve Teknoloji Dergisi, (33), 55-59.

$\ddot{\mathbf{O z}}$

Bu çalışmada, Mg-2.5Al-0.3Mn-0.4La-0.2Gd alaşımı düşük basınçlı kokil kalıba döküm yöntemiyle başarılı bir şekilde üretilmiştir. Döküm sonrası $350^{\circ} \mathrm{C}$ de 4,8 ve 12 saat boyunca homojenleştirme 1 sıl işlemi uygulanmıştır. Kuru ortamda ileri-geri aşınma testleri homojenleştirilmiş numunelere 1,2 ve $3 \mathrm{~kg}$ yük altında uygulanmış ve hacimsel metal kaybı hesaplanmıştır. Aşınma test sonuçları ve mikroyapı arasındaki ilişki optik mikroskop, taramalı elektron mikroskobu ve X-Ray Difraksiyon (XRD) metotları kullanılarak araştırılmıştır.

Anahtar Kelimeler: Mg-Al-Sn esaslı Mg alaşım, La, Gd, Aşınma, Homojenleştirme.

\section{Investigation of The Effect of Homogenization Time on The Wear Behavior of Mg-Al-Sn-Mn-La-Gd Alloy}

\begin{abstract}
In this study, Mg-2.5Al-0.3Mn-0.4La-0.2Gd alloy was successfully produced by low pressure permanent mold casting method. After casting, homogenization heat treatment was applied at $350^{\circ} \mathrm{C}$ for 4.8 and 12 hours. Reciprocating wear tests in dry conditions were applied to homogenized samples under 1,2 and $3 \mathrm{~kg}$ load and volumetric metal loss was calculated. The relationship between wear test results and microstructure was investigated using optical microscope, scanning electron microscope and X-Ray Difraction (XRD) methods.
\end{abstract}

Keywords: Mg-Al-Sn base Mg alloys, La, Gd, Wear, Homogenization.

\footnotetext{
*Sorumlu Yazar: ihakkikara@karabuk.edu.tr
} 


\section{Giriş}

Magnezyum alaşımları yüksek özel mukavemetleri ve düşük yoğunlukları nedeniyle başta otomotiv sektörü olmak üzere birçok alanda talep gören metalik malzemelerdir. Fakat $\mathrm{Mg}$ alaşımlarının aşınma dirençleri düşüktür (Ilanaganar \& Anbuselvan, 2018). Aşınma davranışı kontrolü ve geliştirilmesi için alaşım ilavesi yöntemi alternatif ve etkili bir yöntemdir. Nadir toprak elementleri $\mathrm{Mg}$-Al ikili alaşımların yüksek sıcaklıklardaki mukavemet özelliklerini iyileştirmede kullanılmıştır ve başarılı sonuçlar alınmıştır. Burada düşük erime noktasına sahip $\mathrm{Mg}_{17} \mathrm{Al}_{12}$ ikincil faz yerine yapida $\mathrm{Al}_{2} \mathrm{RE}$ ve $\mathrm{Al}_{11} \mathrm{RE}_{3}$ türünden yüksek sıcaklıklarda kararlı olan ikincil fazlar meydana gelmektedir (Asl, Masoudi, \& Khomamizadeh, 2010). Homojenleştirme 1sıl işlemi döküm sonrası Mg alaşımlarındaki segregasyonları azaltmak için kullanılmaktadır. Alaşım elementinin homojenleştirme süresi ve sıcaklığı gibi parametrelere etkisi bilinmektedir. Üretim maliyeti bakımından homojenleştirme sıcaklığının ve süresinin düşürülmesi yararlı olacaktır (Jena, Naskar, Kumar, \& Paliwal, 2020). Bunun yanında homojenleştirme süresine bağlı tane boyutunda ve ikincil fazların şekil, boyut ve dağılımlarındaki değişim $\mathrm{Mg}$ alaşımların mekanik özelliklerini ve korozyon direncini etkilemektedir. Mg-Al-Sn esaslı $\mathrm{Mg}$ alaşımlarının üstün özellikler sergilediği son yıllardaki çalışmalarda görülmüştür. $\mathrm{Mg}_{2} \mathrm{Sn}$ çökelti sertleşmesi sağlayarak $\mathrm{Mg}$ alaşımlarının mekanik özelliklerini iyileştirmektedir. Buna ilaveten $\mathrm{Sn}$ sayesinde $\mathrm{Mg}$ alaşımın kayma sistemi daha çok aktifleşir. Çünkü tane sınırı sayının oransal artışı gerilmeleri yükseltmektedir bu ise bazal olmayan kayma düzlemlerini aktiflştirmektedir ve böylece hem mukavemet hem de süneklikte artışı sağlamaktadır. Sıcak hadde esnasında yeniden kristalleşen tane sayınındaki artış ortalama tane boyutunda azalmaya ve sonuç olarak daha çok kayma sistemi aktifleşmektedir. Sn ilavesiyle Mg alaşımının istiflenme hata enerjisi (SFE) azalmaktadır. Azalan SFE sayesinde yeniden kristalleşen tanelerin sayısında artış olduğu bilinmektedir (Kabir, Sanjari, Su, Jung, \& Yue, 2014). Mn ise Mg alaşımların özellikle korozyon direncini geliştirmekte kullanılmaktadır. Mn empürite elementlerden demiri yapıdan temizlemektedir. Bunun yanında Mn-Al ikilisi ikincil faz oluşturmakta ve mekanik özellikleri geliştirmektedir (Cug \& Ahlatci, 2017). La ilaveli AZ31 Mg alaşımları üzerine çalışmalar mevcuttur. La-Al ikilisi $\mathrm{Al}_{11} \mathrm{La}_{3}$ ve $\mathrm{Al}_{2} \mathrm{La}$ gibi ikincil faz oluşumu sayesinde $\mathrm{Mg}$ alaşımın mekanik özelliklerini çökelti sertleşmesi sayesinde geliştirmektedir (Wu, ve diğerleri, 2019). Ek olarak, Gd sayesinde AZ31 Mg alaşımlarında homojenleştirme süresinde düşüş sağlandığı bulunmuştur. Ayrıca Gd içeren ikincil fazların mikroyapıda homojen şekilde dağıldığı bildirilmiştir (W.P. Li, 2009). Buna rağmen $\mathrm{La}$ ve $\mathrm{Gd}$ ilaveli $\mathrm{Mg}$-Al-Sn esaslı alaşımların mikroyapısal özellikleri ve aşınma dirençleri hakkında çalışma literatürde çok sınırlı sayıdadır.

$\mathrm{Bu}$ çalışmada, Mg-Al-Sn-Mn-La-Gd alaşımına $350{ }^{\circ} \mathrm{C}$ de 4,8 ve 12 saat boyunca homojenleştirme isıl işlemi uygulanmıştır. Homojenleştirme 1 sıl işleminin mikroyapıya etkisi LOM, SEM ve XRD metotlarıyla araştırılmıştır. Kuru ortamda aşınma davranışları incelemek için 1,2 ve $3 \mathrm{~kg}$ yük altında aşınma testine maruz bırakılmıştır. Sertlik testi sonuçları ile aşınma davranışı arasındaki ilişki irdelenmiştir. Aşınma hızları karşılaştırılan alaşımların değişen yüke bağlı aşınma mekanizmaları incelenmiştir.

\section{Materyal ve Metot}

Mg-Al-Sn-Mn-La-Gd alaşımı düşük basınçlı kokil kalıba döküm yöntemiyle elektrik dirençli ocak kullanılarak üretilmiştir. Saf $\mathrm{Mg}$, Al ve $\mathrm{Sn}$ ilk olarak ocağa yüklenmiştir. 750 ${ }^{\circ} \mathrm{C}$ de 1 saat eritilen malzemelere $\mathrm{Mg}-\mathrm{Mn}, \mathrm{Mg}$-La ve $\mathrm{Mg}-\mathrm{Gd}$ master alaşımları ilave edilmiştir. Öncesinde $350{ }^{\circ} \mathrm{C}$ 'ye 1 sıtılmış paslanmaz çelik kalıplara 1-2 atm. basınç vasıtasıyla eriyik metal enjekte edilmiştir. Üretilen alaşımın kimyasal bileşimi (\%2.5Al, \%1.0Sn, \%0.3Mn, \%0.4La ve \%0,2 Gd kalan Mg. (ağ.ol.)) X 1şını floresansı (XRF-Rigaku Primus II) cihazıyla belirlenmiştir. 10x10x10 mm boyutlarında numuneler $350^{\circ} \mathrm{C}$ de 4,8 ve 12 saat boyunca 1sıl işlem firınında homojenleştirme 1 șl işlemi görmüştür. Süresi dolan numuneler su verilerek soğutulmuştur. Mikroyapısal karakterizasyon öncesi zımparalama (600-2500 kum sayılı), parlatma (1 $1 \mu \mathrm{m}$ elmas süspansiyon) ve dağlama (pikral) işlemleri yapılarak metalografik işlemler tamamlanmıştır. Tanelerin ve ikincil fazların değişimini ortaya çıkarmak için sırasıyla optik mikroskop (LOM- Carl Zeiss 1şık optik mikroskop) ve elektron mikroskobu (Carl Zeiss Ultra Plus taramalı elektron mikroskop) kullanılmıştır. İkincil fazların belirlenmesi için XRD kullanılmıştır. ASTM E112 standardına göre optik mikroskop resimlerinden ortalama tane boyutları hesaplanmıştır. ASTM G-133 standardına göre kuru ortamda ileri-geri aşınma testleri (UTS-Tribometer Test Cihazı) 1,2 ve 3 $\mathrm{kg}$ yük altında uygulanmıştır. $13 \mathrm{~mm}$ stroke mesafesi ayarlanmış ve toplam $100 \mathrm{~m}$ boyunca numuneler aşınma testine maruz kalmıştır. Aşınma sonrası hacimsel kayıp profilometre cihazı kullanılarak belirlenmiştir. Aşınma izine dik yönde her bir numuneden beş adet ölçüm alınmıştır. 2D boyutlu profilometre eğrileri toplam iz boyu ile çarpılarak aşınan hacim miktarı bulunmuştur (ASTM, 1968). Aşınma testi sonrası değişen alaşım elementi miktarı ve aşınma yüküne bağlı ne tür aşınma mekanizması oluştuğu EDX (enerji dağılım X-ray spektrometresi) destekli SEM cihazı kullanılarak bulunmuştur. Numunelerin sertlik ölçümü üniversal sertlik cihazı kullanılarak Brinell yöntemine göre yapılmıştır ( $2.5 \mathrm{~mm}$ çaplı çelik bilye $187.5 \mathrm{~kg}$ yük- $10 \mathrm{sn}$. bekleme süresi).

\section{Araştırma Sonuçları ve Tartışma}

\subsection{Mikroyapı İncelemesi}

Şekil 1'de optik mikroskop kullanılarak elde edilmiş mikroyap1 görüntüleri verilmiştir. Optik mikroskop görüntüleri ortalama tane boyutu ve tanelerin şekli hakkında bilgi vermiştir. Homojenleştirme 1sıl işleminde 8 saat $(\sim 23 \mu \mathrm{m})$ bekletilen numunenin 4 saat ( $\sim 34$ mikron) bekletilen numuneye göre daha küçük taneler içerdiği görülmektedir. Aynı zamanda 8 saat bekletilen numunede daha homojen küresel taneler oluşmuştur. Buna rağmen 12 saat süre ( $\sim 38$ mikron) sonunda en iri taneler elde edilmiştir. Bunun yanında 12 saatlik homojenleştirme süresi sonunda iri taneler içinde dendritik yapılar oluşmuştur.

Şekil 2'de alaşımların içerdiği ikincil fazların görüldüğü SEM görüntüleri verilmiştir. SEM görüntüleri mikroyap1 hakkında ikincil fazların şekil, boyut ve dağılım bakımından bilgi vermektedir. İkincil fazların 4 saatlik homojenleştirme süresi sonunda küresel ve çubuk şeklinde oluştuğu görülmektedir. 4 saat sonundakine göre 8 saat süre sonunda miktar olarak daha çok küresel ikincil faz oluşmuş ve boyut olarak daha iri ikincil fazlar gözlenmiştir ve bazı bölgelerde kümelenen ikincil fazlar karmaşık şekilde oluşmuştur. 12 saat 

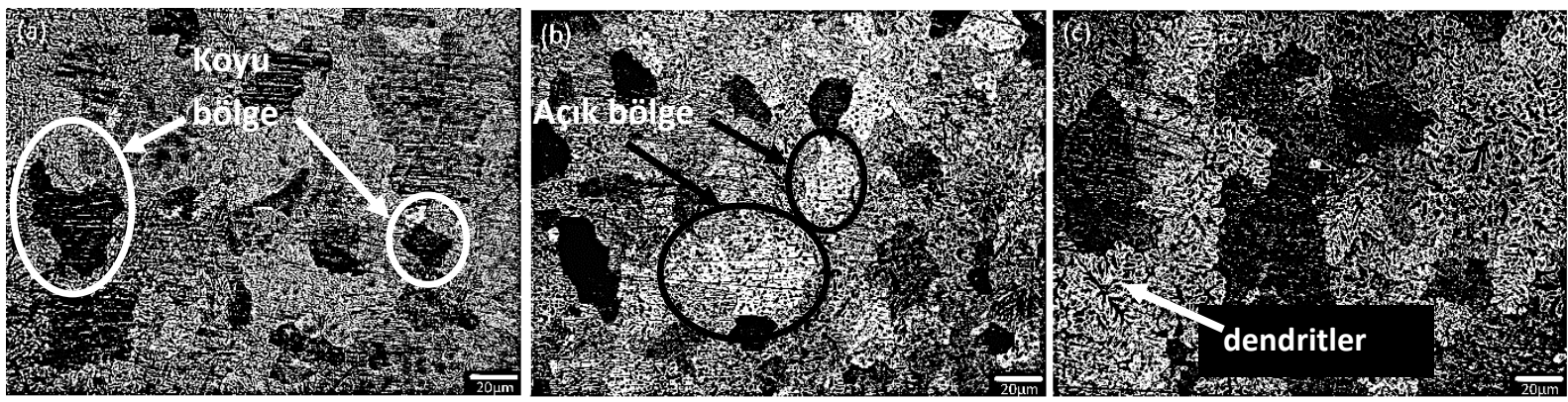

Şekil 1. (a) 4 saat (b) 8 saat (c)12 saat homojenleştirme 1sıl işlemi görmüş numunelere ait LOM görüntüleri.(Figure 1. LOM images of samples treated with homogenization heat treatment along (a) 4 hours (b) 8 hours (c) 12 hours.)
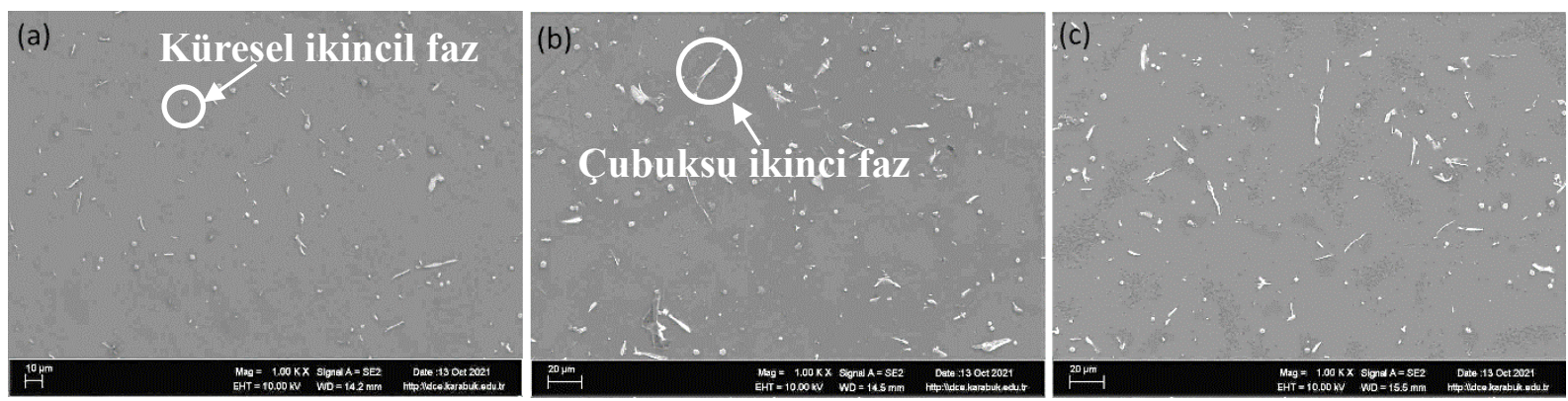

Şekil 2. (a) 4 saat (b) 8 saat (c)12 saat homojenleştirme 1sıl işlemi görmüş numunelere ait SEM görüntüleri. (Figure 2. SEM images of samples treated with homogenization heat treatment along (a) 4 hours (b) 8 hours (c) 12 hours.)

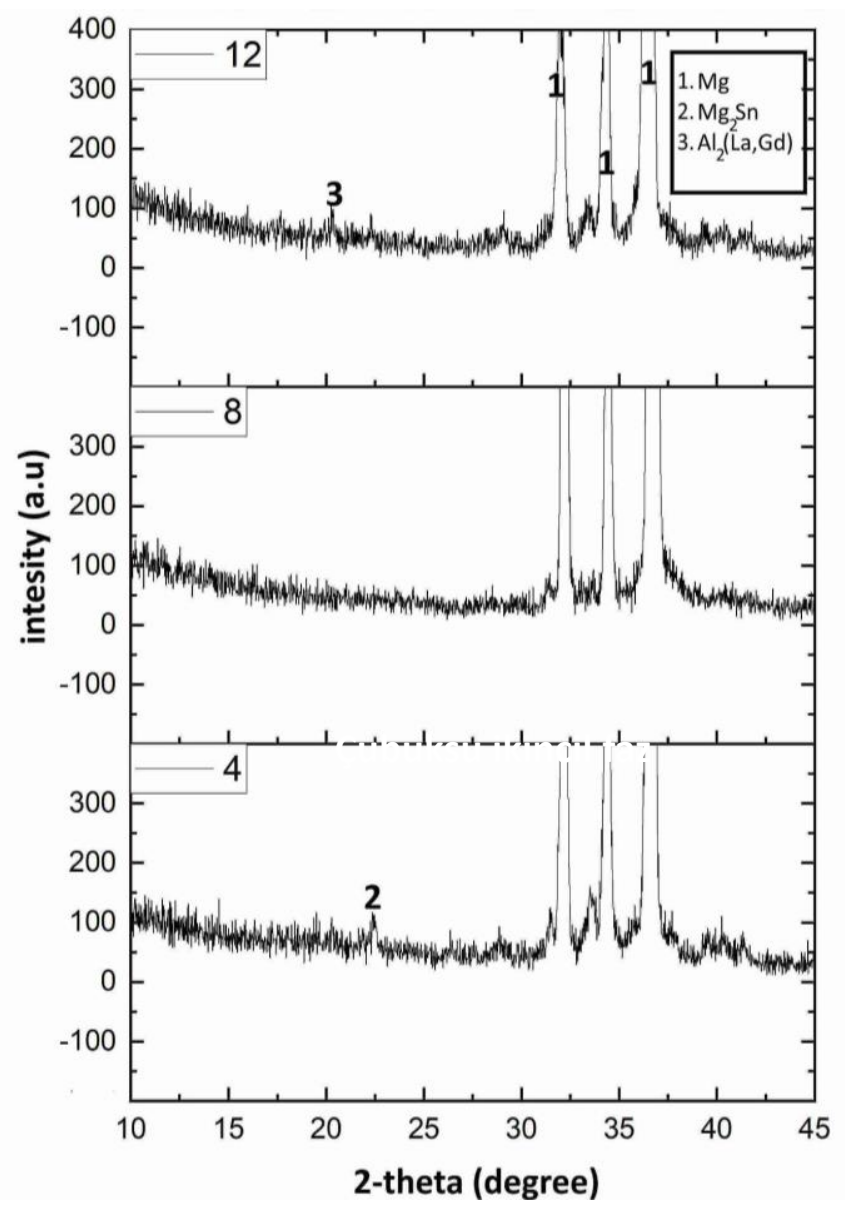

Şekil 3. (a) 4 saat (b) 8 saat (c)12 saat homojenleştirme 1sıl işlemi görmüş numunelere ait XRD paternleri. (Figure 3. XRD patterns of samples treated with homogenization heat treatment along (a) 4 hours (b) 8 hours (c) 12 hours.) 
süre sonunda ince küresel fazlar miktarca azalmış ve ince ve uzun şekilde oluşmuş çubuksu ikincil fazlar mikroyapıda yer edinmiş̧tir (Yang, ve diğerleri, 2018).

Farklı sürelerde homojenleştirme 1 șl işlemi uygulanmış numunelere ait XRD paternleri Şekil 3'de verilmiştir. Açı aralığı (10-45 degree) ve şiddet aralığ $1((-) 300-(+) 400$ a.u.) için ikincil fazlardaki farklar görülmektedir. 4 saat homojenleştirme süresi sonunda $\mathrm{Mg}_{2} \mathrm{Sn}$ (Jena, Naskar, Kumar, \& Paliwal, 2020) ikincil fazı oluşmuştur. Buna rağmen 8 saatlik homojenleştirme isıl işlemi sonunda $\mathrm{Mg}_{2} \mathrm{Sn}$ matriste çözünmüştür. 12 saatlik homojenleştirme sonrası $\mathrm{Mg}_{2} \mathrm{Sn}$ ve $\mathrm{Al}_{2}$ (La, Gd) ikincil fazları mikroyapıda yer edinmiştir (Bu, ve diğerleri, 2016).

\subsection{Sertlik Testi}

Sertlik testi sonuçları 4,8 ve 12 saat homojenleştirilen numunelerin için sirasıyla 54.97 HBW, 51.36 HBW ve 54.16 HBW şeklinde bulunmuştur. En düşük sertlik 8 saat homojenleştirme uygulanan numunede fakat en yüksek sertlik ise 4 saat homojenleştirme isıl işlemi uygulanan numunede elde edilmiştir. Böylece daha kısa sürede daha sert alaşım elde edilmiştir.

\subsection{Aşınma Testi}

Kuru ortam aşınma testi oda sıcaklığında ve $1 \mathrm{~kg}, 2 \mathrm{~kg}$ ve 3 kg yük altında uygulanmıştır ve farklı homojenleştirme süresi uygulanan numuneler için hacimsel kayıplar Tablo 1'de verilmiştir. $1 \mathrm{~kg}$ ve $3 \mathrm{~kg}$ yük altında en fazla hacimsel metal kaybı miktarı 8 saat homojenleştirilmiş numunede ölçülmüştür. Buna rağmen $1 \mathrm{~kg}$ ve $3 \mathrm{~kg}$ yük altında en az hacimsel metal kaybı miktarı 4 saat homojenleştirilmiş numunede elde edilmiştir. Fakat $2 \mathrm{~kg}$ yük altında hacimsel metal kaybı miktarı artan homojenleştirme süresiyle doğru orantılı şekilde artmıştır (bakınız Şekil 4). 4 saat homojenleştirme süresi sonunda oluşan ince küresel şekilli $\mathrm{Mg}_{2} \mathrm{Sn}$ fazı aşınma direncini arttırdığ söylenebilir. Buna rağmen 8 saat homojenleştirme süresi sonunda $\mathrm{Mg}_{2} \mathrm{Sn}$ fazı yapıdan kaybolmuş ve yerine iri yapılı ikincil fazlar ortaya çıkmıştır. Kümeleşen iri yapılı ikincil fazlar 8 saat homojenleşen numunede sertlik kaybına neden olmuştur. $\mathrm{Bu}$ nedenle aşınma direnci zayıflamıştır. 12 saat homojenleştirme ısıl işlemi sonunda yapıda $\mathrm{Al}_{2}(\mathrm{La}, \mathrm{Gd})$ fazı oluşumu sertlikte artışa neden olmuş ve sonuç olarak 8 saat süreli numuneye göre aşınma direnci artmıştır. Ortalama tane boyutu ve ikincil fazların boyutu karşılaştırıldı̆̆ zaman aşınma direncine baskın mekanizmanın ikincil faz olduğu görülmektedir.

\subsection{Aşınmış Yüzeyler}

4, 8 ve 12 saat homojenleştirme 1 sıl işlemi görmüş numunelerin $1 \mathrm{~kg}$ yük altında aşınma testi yapıldıktan sonra yüzeylerden alınmış SEM görüntüleri Şekil 5' de verilmiştir. 4 saat homojenleştirme uygulanmış numune için aşınma yönüne paralel ince çiziklerin yoğun olduğu Şekil 5a'da görülmektedir. 8 saat homojenleştirme uygulanmış numunede derin olukların oluştuğu Şekil 5b'de görülmektedir (Nouri, Sun, \& Li, 2013). 12 saat homojenleştirme uygulanmış numunede pul veya tabakaların kalkması şeklinde kendini gösteren delaminasyon ve ince çizgi türünde aşınma mekanizmaları oluşmuştur (Asl, Masoudi, \& Khomamizadeh, 2010). Aşınmış yüzeylerden alınan mapping türü EDX analizi oksitlenme türü aşınma mekanizmasının en yüksek oranda 4 saat homojenleşmiş numunede oluştuğunu fakat en az oranda 8 homojenleşmiş numunede oluştuğunu belirlenmiştir. İnce çizgi şeklindeki aşınma mekanizmasının en düşük miktarda malzeme kaybına neden olduğu buna rağmen derin oluk aşınma mekanizmasının en yüksek oranda malzeme kaybına sebep olduğu bilinmektedir. Delaminasyon türü aşınma mekanizması sert ikincil fazların karşı malzeme tarafından sürüklenmesi ve farklı bir bölgeye pul veya tabaka şeklinde malzeme taşımasından kaynaklı olduğu söylenebilir. Oksitlenme, devam eden aşınma testi boyunca oksitlenmiş debrisler yüzeydeki olukları doldurmakta ve koruyucu bir tabaka halinde sıkışır bu ara yüzey metalik sürtünmeyi azaltır ve daha az aşınma kaybı oluşur (Kumar, Pillai, Pai, \& Chakraborty, 2013) .

Tablo 1. Aşınma testi sonrası hesaplanan hacimsel kayıp değerleri $\left(\mathrm{mm}^{3}\right)$. (Table 1. The calculated wear rate after wear test)

\begin{tabular}{|c|c|c|c|c|c|}
\hline \multirow{2}{*}{$\begin{array}{c}\text { Homojenleştirme } \\
\text { Süresi } \\
\text { (saat) }\end{array}$} & \multirow{2}{*}{$\begin{array}{l}\text { Brinell } \\
\text { Sertlik } \\
\text { (HBW) }\end{array}$} & \multirow{2}{*}{$\begin{array}{c}\text { Ortalama } \\
\text { Tane } \\
\text { Boyutu } \\
(\mu \mathrm{m})\end{array}$} & \multicolumn{3}{|c|}{ Hacimsel kayıp değerleri $\left(\mathrm{mm}^{3}\right)$} \\
\hline & & & $1 \mathrm{~kg}$ & $2 \mathrm{~kg}$ & $3 \mathrm{~kg}$ \\
\hline 4 & 54.97 & $23 \pm 1.2$ & $1.131 \pm 0.12$ & $1.274 \pm 0.17$ & $2.041 \pm 0.19$ \\
\hline 8 & 51.36 & $34 \pm 0.9$ & $1.872 \pm 0.14$ & $2.093 \pm 0.12$ & $3.055 \pm 0.11$ \\
\hline 12 & 54.16 & $38 \pm 0.8$ & $1.235 \pm 0.18$ & $2.158 \pm 0.18$ & $2.314 \pm 0.16$ \\
\hline
\end{tabular}

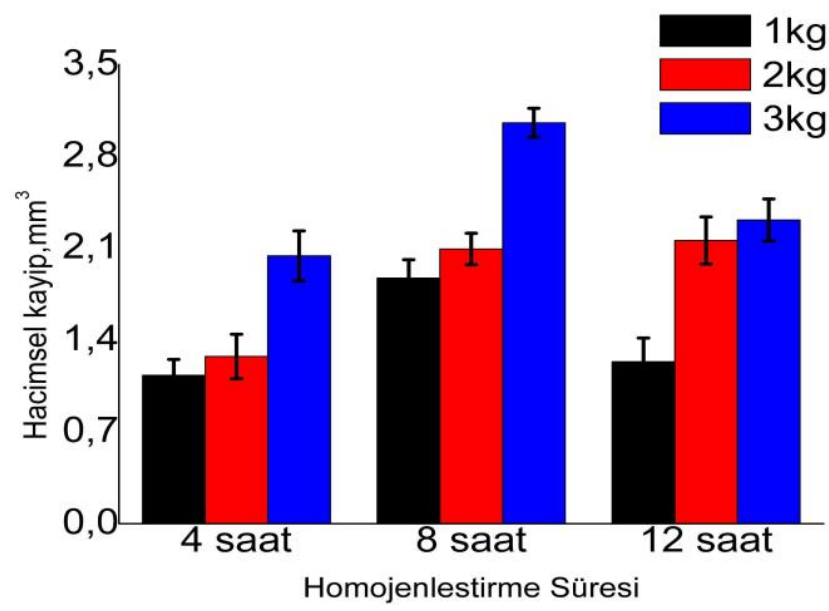

Şekil 4. Farklı sürelerde homojenleştirme 1sıl işlemi uygulanan $\mathrm{Mg}-2.5 \mathrm{Al}-0.3 \mathrm{Mn}-0.4 \mathrm{La}-0.2 \mathrm{Gd}$ alaşımına ait numunelerin $1 \mathrm{~kg}, 2 \mathrm{~kg}$ ve $3 \mathrm{~kg}$ yük altında kaybettikleri hacimsel miktarların karşılaştırılması. (Figure 4. Comparison of the volumetric amounts of Mg-2.5Al-0.3Mn-0.4La-0.2Gd alloy samples, which were subjected to homogenization heat treatment at different times, under $1 \mathrm{~kg}, 2 \mathrm{~kg}$ and $3 \mathrm{~kg}$ loads.) 


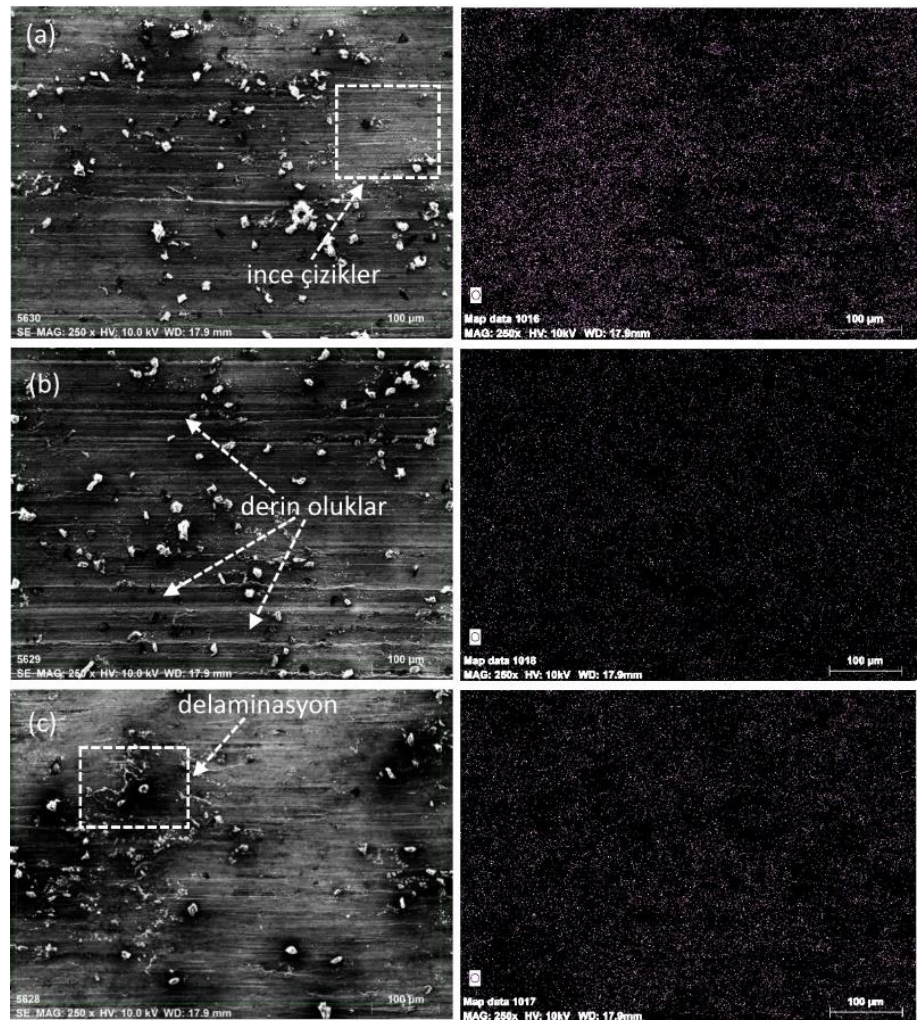

Şekil 5. (a) 4 saat (b) 8 saat (c)12 saat homojenleştirme 1sıl işlemi görmüş numunelere ait $1 \mathrm{~kg}$ yük altında aşınmış yüzey SEM görüntüleri. (Figure 5. Worn surface SEM images under 1 kg load. (a) 4 hours (b) 8 hours (c) 12 hours of homogenization heat-treated samples.)

\section{Sonuç}

Mg-2.5Al-0.3Mn-0.4La-0.2Gd alaşımları düşük basınçlı kokil kalıba döküm yöntemiyle üretildikten sonra 4,8 ve 12 saat $350^{\circ} \mathrm{C}$ ' de homojenleştirme 1 sil işlemine tabi tutulmuştur. Mikroyapı analizleri, sertlik ve aşınma testleri sonucu aşağıdaki maddeler elde edilmiştir.

1. Homojenleştirme süresine bağlı farklı şekillerde ve boyutlarda taneler görülmüştür. 4 ve 8 saat sonunda küresel tanelerin baskın olduğu fakat 12 saat süre sonunda tanelerin irileştiği bunun yanında dendritler şeklinde bölündüğü bulunmuştur.

2. Sertlik değerleri kıyaslandığı zaman irileşen ikincil fazların 8 saat homojenleştirme 1sıl işlemi görmüş numunede en düşük sertliğe neden olduğu anlaşılmıştır.

3. Düşük sertlik nedeniyle hacimsel malzeme kaybı en yüksek 8 saat homojenleştirme 1sıl işlemi görmüş numunede ölçülmüştür.

4. Aşınma mekanizması olarak ince çizgi, oluk, delaminasyon ve oksidasyon türleri ile karşılaşılmıştır. 8 saat homojenleştirme 1sıl işlemi görmüş numunede görülen derin oluklar en yüksek oranda hacimsel malzeme kaybına neden olmuştur. Buna rağmen ince çizgilerin baskın olduğu 4 saat homojenleştirme 1 șl işlemi görmüş numunede hacimsel malzeme kaybı en azdır.

\section{Kaynakça}

Asl, K., Masoudi, A., \& Khomamizadeh, F. (2010). The effect of different rare earth elements content on microstructure, mechanical and wear behavior of $\mathrm{Mg}-\mathrm{Al}-\mathrm{Zn}$ alloy. Materials Science and Engineering: A, 527(7-8), s. 20272035.

ASTM. (1968). Evaluation of Wear Testing. San Francisco: American Society for Testing and Materials.

Bu, F., Yang, Q., Guan, K., Qoi, X., Zhang, D., Sun, W., . . . Meng, J. (2016). Study on the mutual effect of La and Gd on microstructure and mechanical properties of $\mathrm{Mg}-\mathrm{Al}-\mathrm{Zn}$ extruded alloy. 688, 1241-1250.

Cug, H., \& Ahlatci, H. (2017). Effect of Zn and Mn Additions on the Wear Resistance Cast Alloy Mg-5\%Al-1\%Si. Metal Science and Heat Treatment, 59(7-8), 161-167.

Ilanaganar, E., \& Anbuselvan, S. (2018). Wear mechanisms of AZ31B magnesium alloy during dry sliding condition. Materials Today: Proceedings, 5, s. 628-635.

Jena, A., Naskar, N., Kumar, N., \& Paliwal, M. (2020). Investigation of As-Cast and Homogenized Microstructure in Mg-6 wt\% Sn-1 wt\% Al Alloy: An Experimental and Modelling Study. Metals and Materials International, 1-13.

Kabir, A., Sanjari, M., Su, J., Jung, I.-H., \& Yue, S. (2014). Effect of strain-induced precipitation on dynamic recrystallization in $\mathrm{Mg}-\mathrm{Al}-\mathrm{Sn}$ alloys. Materials Science and Engineering: A, 616, 252-259.

Kumar, K., Pillai, U., Pai, B., \& Chakraborty, M. (2013). Dry sliding wear behaviour of Mg-Si alloys. Wear, 303(1-2), 5664.

Nouri, M., Sun, X., \& Li, D. (2013). Beneficial effects of yttrium on the performance of $\mathrm{Mg}-3 \% \mathrm{Al}$ alloy during wear, corrosion and corrosive wear. 67, s. 154-163.

W.P. Li, H. Z. (2009). Effect of gadolinium on microstructure and rolling capability of AZ31 alloy. Journal of Alloys and Compounds, 227-232. 